\title{
Article \\ Effect of Ferritic Morphology on Yield Strength of CGHAZ in a Low Carbon Mo-V-N-Ti-B Steel
}

\author{
Leping Wang ${ }^{1,2}$, Huibing Fan ${ }^{1,2}$, Genhao Shi ${ }^{1,2}$, Qiuming Wang ${ }^{1,2}$, Qingfeng Wang ${ }^{1,2, *}$ and Fucheng Zhang ${ }^{1,2}$ \\ 1 State Key Laboratory of Metastable Materials Science and Technology, Yanshan University, \\ Qinhuangdao 066004, China; wlp97@stumail.ysu.edu.cn (L.W.); 15033576807@163.com (H.F.); \\ shigenhao@foxmail.com (G.S.); wqm931028@stumail.ysu.edu.cn (Q.W.); 1 r11767@163.com (F.Z.) \\ 2 National Engineering Research Center for Equipment and Technology of Cold Strip Rolling, \\ Yanshan University, Qinhuangdao 066004, China \\ * Correspondence: wqf67@ysu.edu.cn
}

Citation: Wang, L.; Fan, H.; Shi, G.; Wang, Q.; Wang, Q.; Zhang, F. Effect of Ferritic Morphology on Yield Strength of CGHAZ in a Low Carbon Mo-V-N-Ti-B Steel. Metals 2021, 11, 1863. https://doi.org/10.3390/ met11111863

Academic Editor: Dong-Woo Suh

Received: 8 October 2021

Accepted: 14 November 2021

Published: 19 November 2021

Publisher's Note: MDPI stays neutral with regard to jurisdictional claims in published maps and institutional affiliations.

\begin{abstract}
For investigating the impact of ferritic morphology on yield strength (YS) of the highheat-input welding induced coarse-grained heat-affected zone (CGHAZ) of a low carbon Mo-V$\mathrm{N}-\mathrm{Ti}-\mathrm{B}$ steel, a group of particular welding heat inputs were designed to obtain different ferritic microstructures in CGHAZ. The tensile properties were estimated from typical samples with ferritic microstructures. The mixed microstructures dominated by the intragranular polygonal ferrite (IGPF), the intragranular acicular ferrite (IGAF), and the granular bainite (GB) were obtained at the heat inputs of 35, 65, 85 and $120 \mathrm{~kJ} / \mathrm{cm}$, respectively. When the main microstructure changed from IGPF to IGAF and GB, YS increased first and then decreased. The microstructure consisting mainly of IGAF possessed the maximum YS. As the main microstructure changed from IGPF to IGAF and GB, the contribution of grain refinement strengthening to YS was estimated to be elevated remarkably. This means the strength of CGHAZ in a low-carbon steel subjected to the high-heat-input welding could be enhanced by promoting the fine-grained AF and GB formation.
\end{abstract}

Keywords: low carbon Mo-V-N-Ti-B steel; CGHAZ; ferritic morphology; yield strength; high-heatinput-welding

\section{Introduction}

Low-carbon microalloying (LCM) steels are widely applied for fabricating vital facilities such as heavy-duty steel bridges, thick-walled vessels, high-rise buildings, largediameter pipelines, etc., via a high heat-input multi-wire arc welding for improving manufacturing efficiency [1-3]. The harmful microstructures such as the coarse polygonal ferrite $(\mathrm{PF})$, granular bainite, and the martensite/austenite (M/A) constituent, however, may form in the CGHAZ of such a LCM steel subjected to the high heat-input welding (HHIW, normally with the heat input, $\mathrm{E}_{\mathrm{j}}$, of $50 \mathrm{~kJ} / \mathrm{cm}$ or higher) due to a prolonged dwelling time at high temperature $\left(\geq 130^{\circ} \mathrm{C}\right.$, for example) and a decreased cooling rate $\left(\leq 1{ }^{\circ} \mathrm{C} / \mathrm{s}\right.$, for example), accordingly leading to a serious degradation of both cryogenic toughness [4] and strength [5]. Extensive investigations [6,7] have demonstrated that the intragranular ferrite (IGF) nucleating at some non-metallic inclusions [8] and/or complex precipitates $[9,10]$ and arranging in a high misorientation tolerance angle (MTA $\geq 15^{\circ}$ ) structure [11] can result in a remarkably refined and accordingly toughened microstructure in CGHAZ. Thus, exploration and application of this metallurgical method to enhance the mechanical properties of the welding induced CGHAZ have always been focused as one of the most concerned issues [12-14].

The low-carbon V-N-Ti steel has a high IGF nucleation capacity and thereby a good toughness in its CGHAZ induced by the HHIW, which has attracted increasingly wide attention [5,9,15-19]. Hongyan Wu et al. [20] concluded that the addition of only $0.021 \mathrm{wt} . \%$ $\mathrm{Nb}$ into a $\mathrm{V}$ microalloyed steel could not promote the formation of ferrite in its reheating 
coarse grain heat affected zone on account of the dispersed $\mathrm{V}(\mathrm{C}, \mathrm{N})$ precipitates effectively motivating ferrite nucleation. An early work by Kook-soo Bang et al. [21] reported that the cryogenic toughness at $-20{ }^{\circ} \mathrm{C}$ of the CGHAZ in a nitrogen-enhanced V-Ti steel was significantly improved compared with that of the nitrogen-free steel. This was attributed to the enhanced IGF nucleation by the nitrogen addition. As Zhang et al. [22] subsequently pointed out, the addition of only $0.0064 \mathrm{wt} . \% \mathrm{~N}$ into a low carbon V-Ti steel could promote the formation of IGPF in its CGHAZ. Zhongran Shi and Qingfeng Wang et al. [5] further elucidated that a V-rich cap around the Ti-rich $(\mathrm{Ti}, \mathrm{V})(\mathrm{C}, \mathrm{N})$ complex precipitate in the CGHAZ of a low-C V-N-Ti steel with the N content from 0.009 to 0.019 wt. $\%$ subjected to the HHIW (typically with the $E_{j}=100 \mathrm{~kJ} / \mathrm{cm}$ ) promote the IGPF nucleation via lowering crystal lattice mismatch, and hence significantly improved the cryogenic toughness of CGHAZ at -20 and $-40{ }^{\circ} \mathrm{C}$.

However, the HHIW-induced CGHAZ mainly consisting of the IGPF normally has a relative low yielding strength (YS). As reported by J. Hu et al. [12], The IGPF with average size of $8.3 \mu \mathrm{m}$, developing in the intercritically reheated CGHAZ of a $0.08 \mathrm{C}-0.06 \mathrm{~V}-0.009 \mathrm{~N}-$ Ti steel, resulted in both a high charpy-V-notch impact energy at $-20{ }^{\circ} \mathrm{C}$ of $260 \mathrm{~J}$ and a relatively low YS of only $345 \mathrm{MPa}$. Moreover, according to Zhongran Shi and Qingfeng Wang et al. [5], the simulated CGHAZ of 0.077C-0.06V-0.0091N steel at the welding heat input of $125 \mathrm{KJ} / \mathrm{cm}$ was almost entirely composed of IGPF due to the nitrogen addition, exhibiting an enhanced cryogenic impact toughness, but at the expense of YS (less than $345 \mathrm{MPa}$ ). Meanwhile, with the addition of $0.26 \mathrm{wt} . \%$ Mo into a $0.06 \mathrm{C}-0.06 \mathrm{~V}-0.014 \mathrm{~N}$ steel, this IGPF was replaced by an IGAF, while the YS was elevated to a higher grade of 418 498 MPa [18]. Moreover, with the addition of both $0.28 \mathrm{wt} \%$ Mo and $0.0012 \mathrm{wt} \% \mathrm{~B}$ into a $0.06 \mathrm{C}-0.06 \mathrm{~V}-\mathrm{N}$ steel and the increasing nitrogen content from 0.0085 to $0.0144 \mathrm{wt}$. $\%$, the cryogenic toughness of simulated CGHAZ was improved remarkably, due to the formation of a mixed microstructure consisting of IGPF, IGAF and GB with a smaller equivalent grain size and a higher fraction of IGAF [19]. Therefore, the IGAF also normally nucleates at some non-metallic inclusions [23] and/or complex precipitates [24], but has a finer interlocking structure [25], suggesting an elevated YS besides an enhanced toughness, compared with the IGPF. However, the relevant efforts have rarely been reported [26].

In addition, Walter L. Costin et al. [27] once reported that the mechanical properties of AF in X70 steel were similar to that of upper bainite (UB), whereas the resistance of UB to fracture made more contribution to plastic deformations than the former. Sang-In Leea et al. [28] recently indicated that the GB and PF were the major factors affecting the yield ratio and the uniform elongation of bainitic steel, respectively. Anyway, the microstructure in CGHAZ of LCM steel is usually composed of two, three or all, of IGPF, IGAF, GBF and lath bainitic ferrite (LBF). Namely, one microstructural constituent usually coexists and interacts with others. Therefore, their individual contributions to the YS remain still unclear.

In this paper, comparative studies on the impact of the individual microstructure of IGPF, IGAF and GB in simulated CGHAZ of low-carbon Mo-V-N-Ti-B steel on the tensile properties were performed specially with differing heat inputs for preparing them. The mechanisms controlling their contributions to the YS were also analyzed systematically.

\section{Experimental}

The chemical composition of the low-carbon Mo-V-Ti-B steel, which was typical traditional bainite steel smelted in a $50 \mathrm{~kg}$ vacuum kiln, was $0.06 \mathrm{C}-0.27 \mathrm{Si}-1.53 \mathrm{Mn}-0.28 \mathrm{Mo}-$ 0.018Ti-0.064V-0.0144N-0.0012B (wt.\%). After the austenitization at $1200{ }^{\circ} \mathrm{C}$ for $2 \mathrm{~h}$, the billets were controlled rolling and cooling. The start and end temperatures of rough rolling were $1100{ }^{\circ} \mathrm{C}$ and $1020^{\circ} \mathrm{C}$, respectively, and the cumulative reduction was $80 \mathrm{~mm}$. The start and end temperatures of finishing rolling were $960^{\circ} \mathrm{C}$ and $850{ }^{\circ} \mathrm{C}$, respectively, and the accumulative decrease was $52 \mathrm{~mm}$. After reaching the final thickness of $18 \mathrm{~mm}$, the steel plates were water-cooled from 800 to $420{ }^{\circ} \mathrm{C}$ at a cooling rate of $15^{\circ} \mathrm{C} / \mathrm{s}$, and then air-cooled to room temperature. 
To research the influence of the main-type microstructure on the tensile properties of HAZ, the following thermal processes were simulated as shown in Figure 1. The simulated samples $(10.5 \mathrm{~mm} \times 10.5 \mathrm{~mm} \times 80 \mathrm{~mm})$ were picked from the plates along the longitudinal direction. Thermal simulations were processed by the Gleeble-3800 thermal simulator (Dynamic Systems Inc., New York, NY, USA) with the heat inputs of 120, 85, 65 and $35 \mathrm{~kJ} / \mathrm{cm}$, respectively. The samples were heated to $1320^{\circ} \mathrm{C}$ at $100{ }^{\circ} \mathrm{C} / \mathrm{s}$, held for $1 \mathrm{~s}$, and cooled according to the thermal cycle curve measured via the Rykalin mode. After finishing these thermal processes, the thermal simulation samples with typical microstructures were obtained. The temperature-time curves and temperature-C-Gauge curves of simulated samples at heat inputs of 25,50,75, 100, 150 and $200 \mathrm{~kJ} / \mathrm{cm}$ were collected during Gleeble program operation to draw the simulated HAZ continuous cooling transformation (SHCCT) diagram.

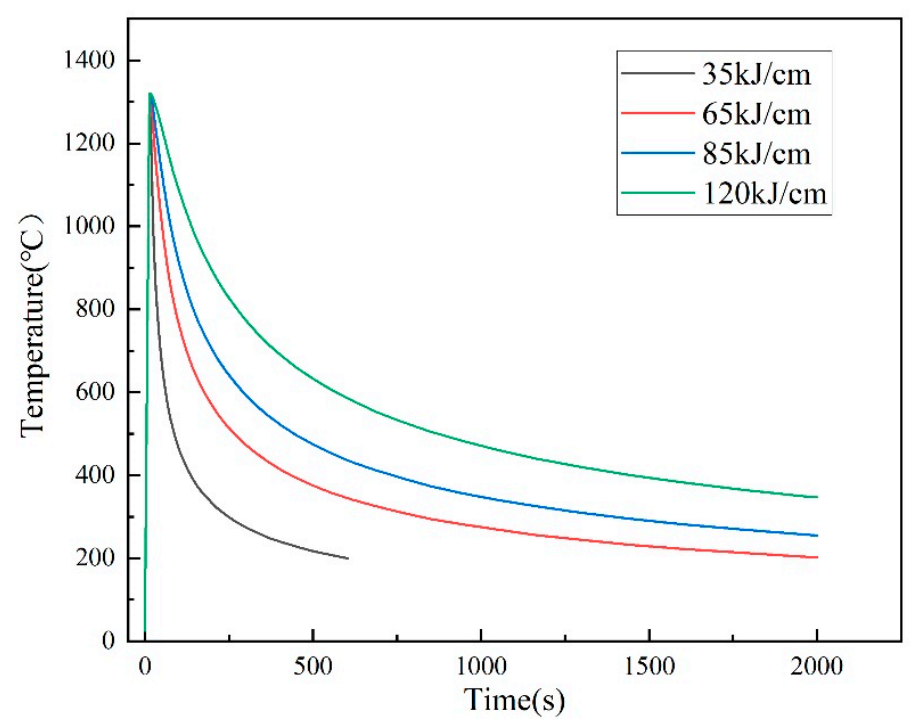

Figure 1. Schematic diagram of the procedures of the thermal processing simulations.

The simulated samples were processed into the micro-tensile samples as shown in Figure 2. The micro-scale tensile test was performed on the Inspekt Table $5 \mathrm{KN}$ model general testing machine (Hegewald\&Peschke, Freiberg, Germany) with an extension rate of $1 \mathrm{~mm} / \mathrm{min}$ at room temperature [29]. Two tensile samples with the same typical microstructures formed at each heat input were prepared and averaged. Since the tensile curve had no yield platform, $0.2 \%$ offset stress was taken as the yield strength.

The metallographic samples sliced from the simulated samples at the location of the thermocouple along the cross-section were observed by the Olympus BX51M optical microscope (Olympus, Aizu, Japan) manufactured by standard techniques and etched with $3 \%$ nitric acid alcohol solution after buffing. Furthermore, JEM-2010 high-resolution transmission electron microscopy (TEM, Japan Electronics optics Corporation, Tokyo Prefecture, Japan) was used to investigate the precipitated particles, the dislocation, the microstructure characteristics, and the M/A constituent by examining the samples of carbon extraction replicas and thin foils. In addition, componential analysis of the precipitates was determined by energy-dispersive X-ray spectroscopy (EDS, Hitachi Limited, Tokyo, Japan). The average particle size and the area fraction were statistically analyzed by the Image Pro-Plus software (Image-Pro ${ }^{\circledR}$ Plus, Media Cybernetics, Bethesda, MD, USA). The X-ray diffraction (XRD) data were acquired by the Rigaku D/Max-2500/PC diffractometer (Rigaku Corporation, Tokyo Prefecture, Japan). The measurements were performed in the scanning angle

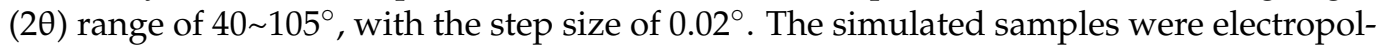
ished in a solution of perchloric acid and ethyl alcohol and observed the misorientation distribution by the electron backscatter diffraction (EBSD, Hitachi Limited, Tokyo, Japan) measurements which were performed in the S-3400 scanning electron microscope (SEM, 
Hitachi Limited, Tokyo, Japan) having a scan step size of $0.2 \mu \mathrm{m}$. The mean equivalent diameter (MED) of the microstructures at different misorientation tolerance angles (MTAs) was detected by EBSD.

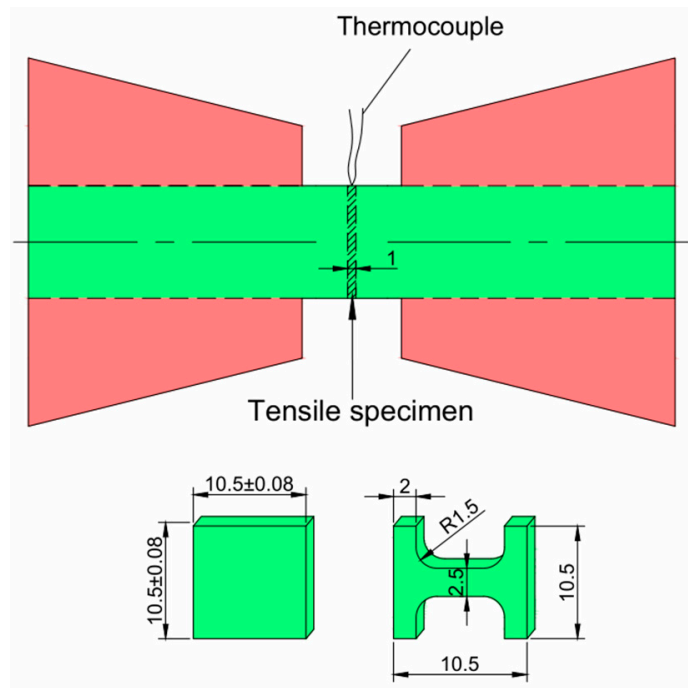

Figure 2. Schematical diagram of the lateral section of the simulated sample for the micro-tensile experiment (in $\mathrm{mm}$ ).

\section{Results}

\subsection{Tensile Properties}

The stress-strain curves of the simulated samples are shown in Figure 3. The tensile mechanical properties are shown in Table 1 . When the heat input gradually decreased from 120 to $65 \mathrm{~kJ} / \mathrm{cm}$, YS sharply increased from 394 to $610 \mathrm{MPa}$, and the tensile strength (TS) slightly increased from 707 to $818 \mathrm{MPa}$. When the heat input gradually decreased from 65 to $35 \mathrm{~kJ} / \mathrm{cm}$, YS slightly decreased from 610 to $545 \mathrm{MPa}$, and TS slightly decreased from 818 to $732 \mathrm{MPa}$.

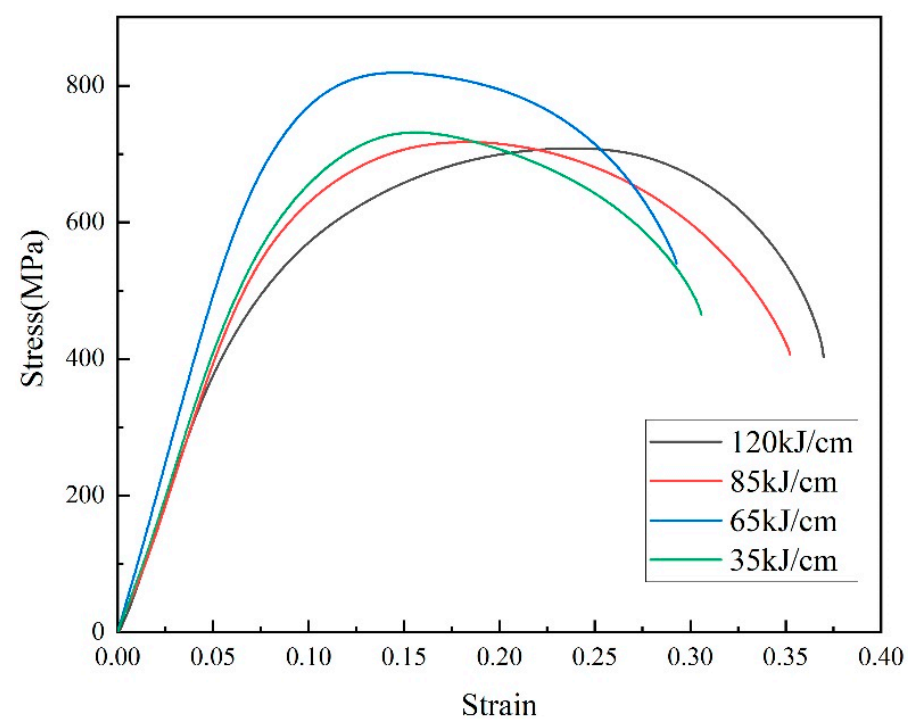

Figure 3. Stress-strain curves. 
Table 1. Tensile mechanical properties.

\begin{tabular}{ccc}
\hline Heat Input/kJ/cm & YS/MPa & TS/MPa \\
\hline 120 & $394 \pm 7$ & $707 \pm 14$ \\
85 & $486 \pm 9$ & $717 \pm 14$ \\
65 & $610 \pm 12$ & $818 \pm 16$ \\
35 & $545 \pm 10$ & $732 \pm 14$ \\
\hline
\end{tabular}

\subsection{Microstructure Observations}

Typical optical microscopy observations of the simulated samples with different heat inputs are shown in Figure 4. The microstructural observations and the measurement results are shown in Table 2. Figure 5 displays the SHCCT diagram of thermal simulated samples. Combined with the SHCCT diagram and microstructural observations it can be seen that the CGHAZ microstructure of simulated samples fluctuated greatly under continuous cooling transformation with different heat inputs. The sample with the heat input of $120 \mathrm{~kJ} / \mathrm{cm}$ consisted of IGPF and pearlite $(\mathrm{P})$. With a decrease in the heat input from 120 to $65 \mathrm{~kJ} / \mathrm{cm}$, P decreased until it disappeared, and the type of ferrite changed from IGPF to IGAF + GB. As the heat input decreased from 65 to $35 \mathrm{~kJ} / \mathrm{cm}$, the fraction of GB increased and the fraction of IGAF gradually decreased.
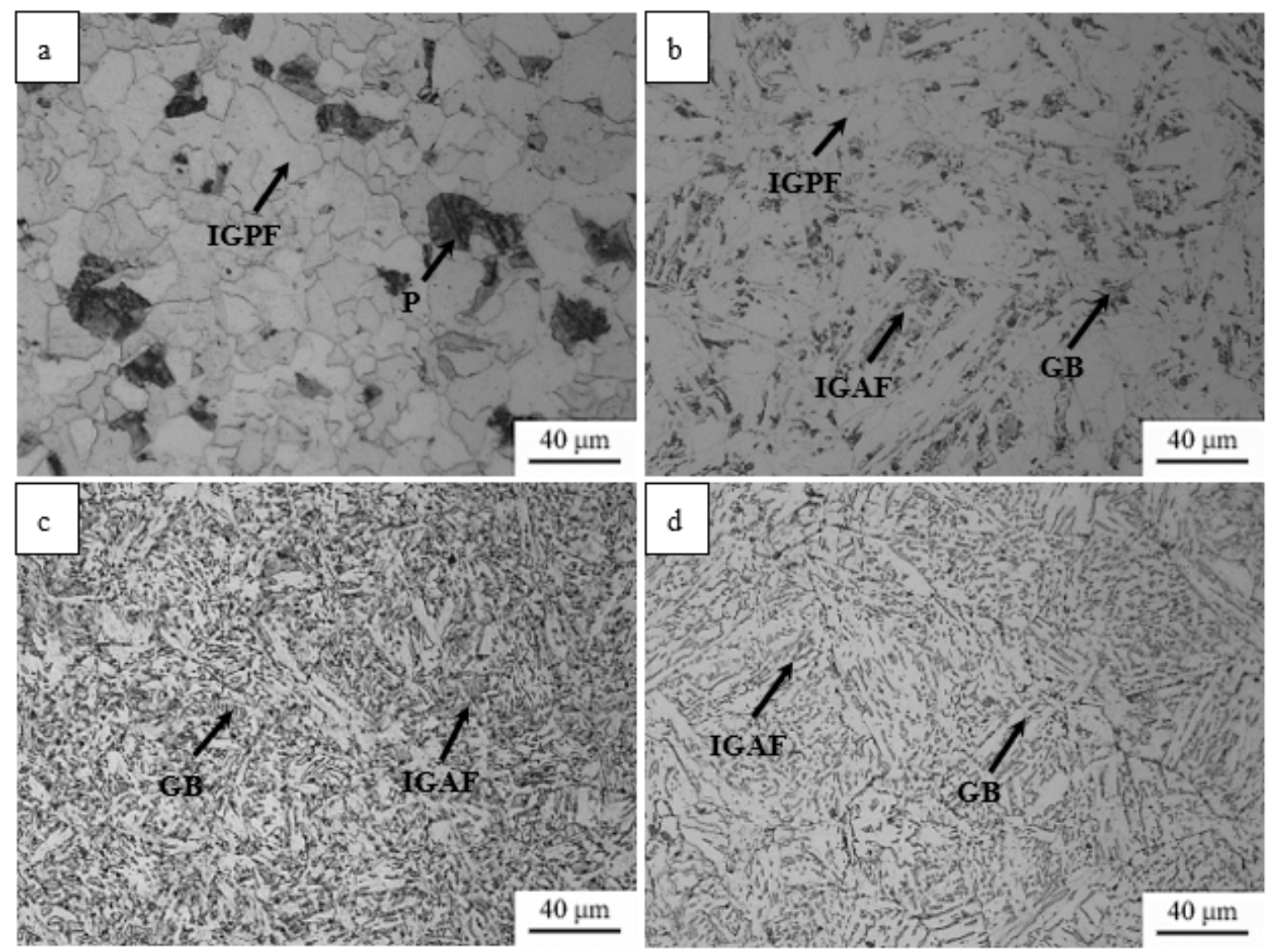

Figure 4. Optical micrographs of the simulated samples of (a) $120 \mathrm{~kJ} / \mathrm{cm},(\mathbf{b}) 85 \mathrm{~kJ} / \mathrm{cm},(\mathbf{c}) 65 \mathrm{~kJ} / \mathrm{cm}$, and (d) $35 \mathrm{~kJ} / \mathrm{cm}$. 
Table 2. Summary of the microstructure examinations and quantification.

\begin{tabular}{|c|c|c|c|c|c|c|c|}
\hline $\begin{array}{c}\text { Heat } \\
\text { Input } / \mathrm{kJ} / \mathrm{cm}\end{array}$ & $\begin{array}{l}\text { Phase Composition } \\
\text { Fraction } / \%\end{array}$ & $f_{\mathrm{M} / \mathrm{A}} / \%$ & $f_{2^{\circ} \leq \theta \leq 15^{\circ}} / \%$ & $\mathrm{MED} / \mu \mathrm{m}$ & $D_{\mathrm{p}} / \mathrm{nm}$ & $f_{\mathrm{p}} / \%$ & $\rho / \times 10^{14} \mathrm{~m}^{-2}$ \\
\hline 120 & $92 \% \mathrm{IGPF}+8 \% \mathrm{P}$ & - & 34 & 24.48 & $33.4 \pm 0.2$ & $10.2 \pm 0.5 \times 10^{-4}$ & 1.47 \\
\hline 85 & $\begin{array}{c}51 \% \mathrm{IGPF}+22 \% \mathrm{IGAF}+6 \% \mathrm{~GB} \\
+2 \% \mathrm{P}\end{array}$ & $13.1 \pm 0.2$ & 55 & 7.86 & $27.8 \pm 0.5$ & $6.9 \pm 0.2 \times 10^{-4}$ & 2.63 \\
\hline 65 & $80 \% \mathrm{IGAF}+6 \% \mathrm{~GB}+2 \% \mathrm{IGPF}$ & $12.4 \pm 0.4$ & 64 & 2.83 & $27.1 \pm 0.2$ & $6.5 \pm 0.3 \times 10^{-4}$ & 3.36 \\
\hline 35 & $79 \% \mathrm{~GB}+11 \% \mathrm{IGAF}$ & $9.8 \pm 0.3$ & 75 & 4.88 & $17.6 \pm 0.3$ & $4.9 \pm 0.3 \times 10^{-4}$ & 3.78 \\
\hline
\end{tabular}

$f_{\mathrm{M} / \mathrm{A}}$ - the area fraction of the $\mathrm{M} / \mathrm{A}, f_{2^{\circ}<\theta<15^{\circ}}$-the fraction of boundaries at low misorientation tolerance angle in the range of 2-15 , $D_{\mathrm{p}}$-the average size of precipitates, $f_{\mathrm{p}}$ - the volume fraction of precipitates, $\rho$ - the dislocation density.

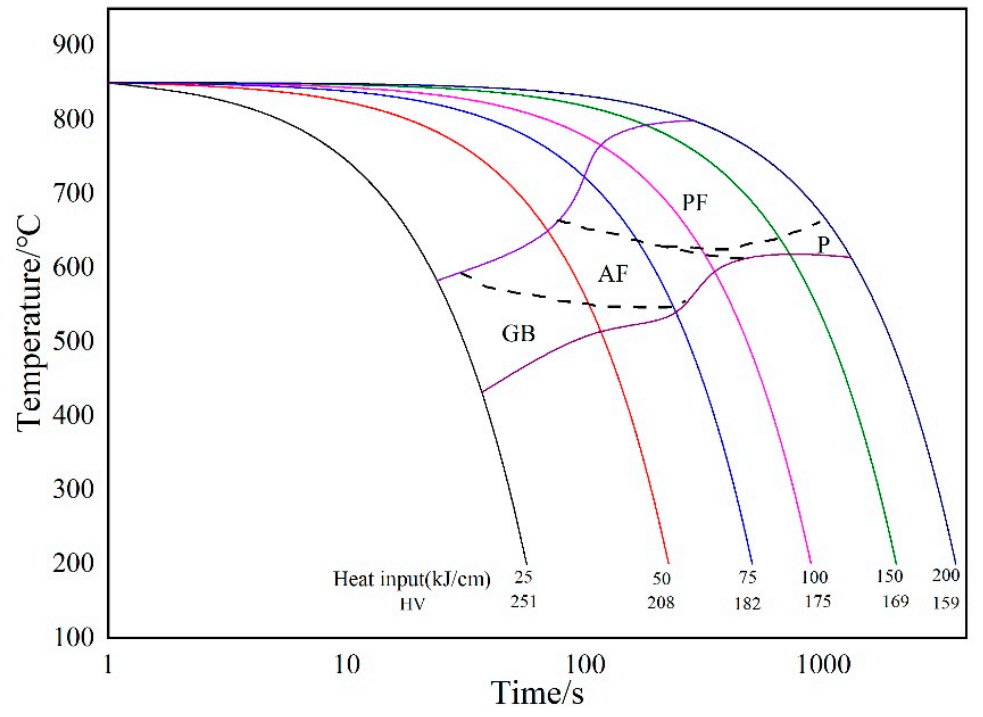

Figure 5. The SHCCT diagram of thermal simulated simples.

According to the TEM observation of multiple fields of the view of the samples with different heat inputs, there were abundant IGPF and lamellar P in the simulated sample of the heat input of $120 \mathrm{~kJ} / \mathrm{cm}$ (Figure 6a). At the heat input of $65 \mathrm{~kJ} / \mathrm{cm}$, the microstructure was mainly composed of intersecting IGAF plates and blocky GB plates (Figure $6 \mathrm{~b}$ ). Figure $6 \mathrm{c}$ shows that at the heat input of $35 \mathrm{~kJ} / \mathrm{cm}$, the microstructure was mainly composed of parallel GB plates. According to the observation of the bright field image and the dark field image as well as the diffraction pattern of the selected area (Figure $6 \mathrm{~d}-\mathrm{f}$ ), the island structure was a constituent phase composed of martensite and austenite. As the heat input decreased from 85 to $35 \mathrm{~kJ} / \mathrm{cm}$, the area fraction and the average size of the M/A decreased from 13.1 to $9.8 \%$ and from 23 to $0.8 \mu \mathrm{m}$, respectively. Moreover, the form of the M/A changed from blocky to slender. The blocky M/A at the intersection of the IGAF plates and the slender M/A were distributed at the boundary of the GB plates.

The quantitative statistical results of the mean size and the volume fraction of the precipitates in each simulated sample are shown in Table 2. As is shown in Figure 7, When the heat inputs gradually decreased from 120 to $65 \mathrm{~kJ} / \mathrm{cm}$, the amount and the average diameter of the precipitates decreased and the precipitates were determined as $(\mathrm{Ti}, \mathrm{V})(\mathrm{C}, \mathrm{N})$, analyzed by EDS. 

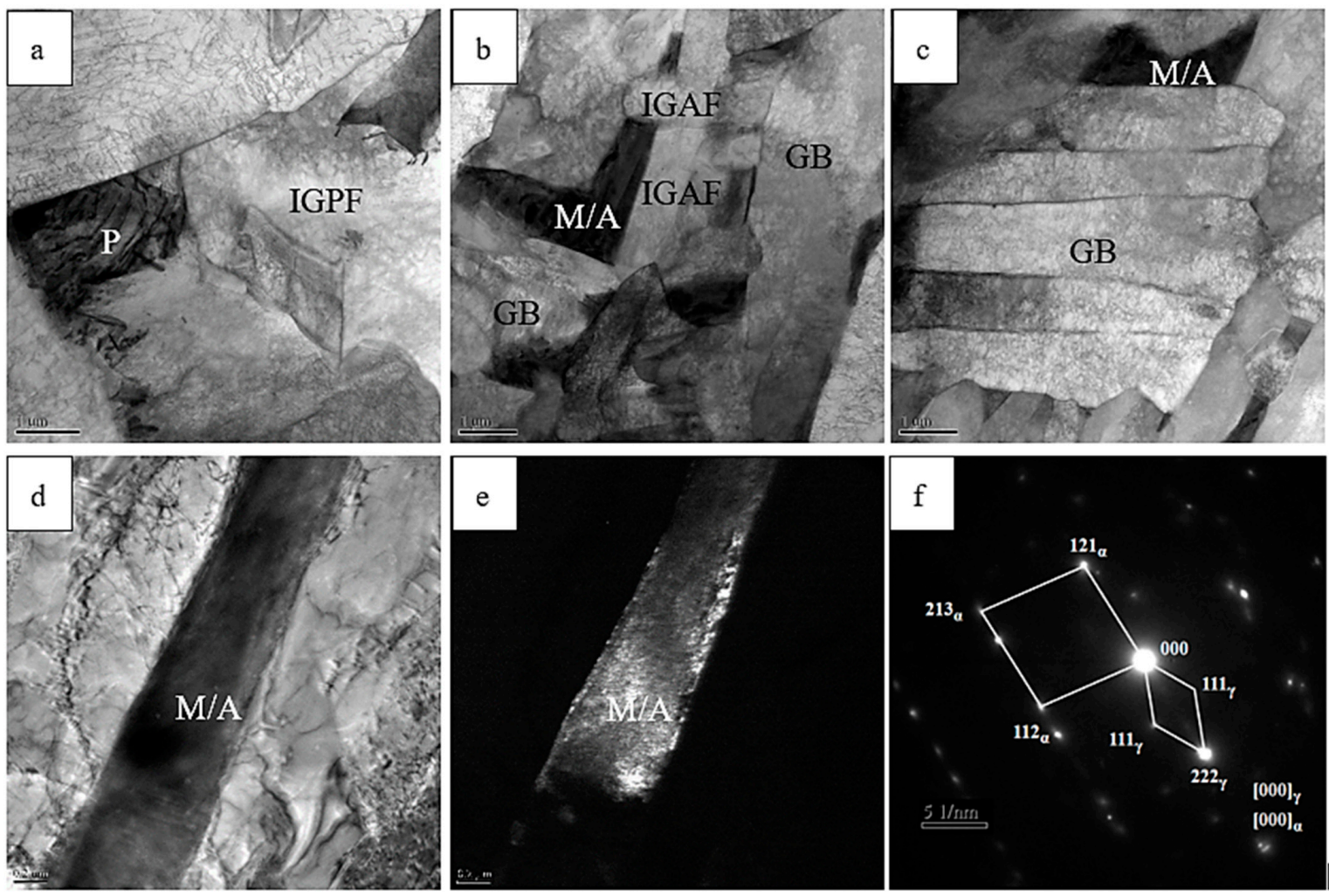

Figure 6. TEM micrographs of the microstructure of the simulated samples of (a) $120 \mathrm{~kJ} / \mathrm{cm},(\mathbf{b}) 65 \mathrm{~kJ} / \mathrm{cm}$, and (c) $35 \mathrm{~kJ} / \mathrm{cm}$, and the M/A manifested by (d) bright field and (e) dark field, and (f) diffraction pattern of the selected area.

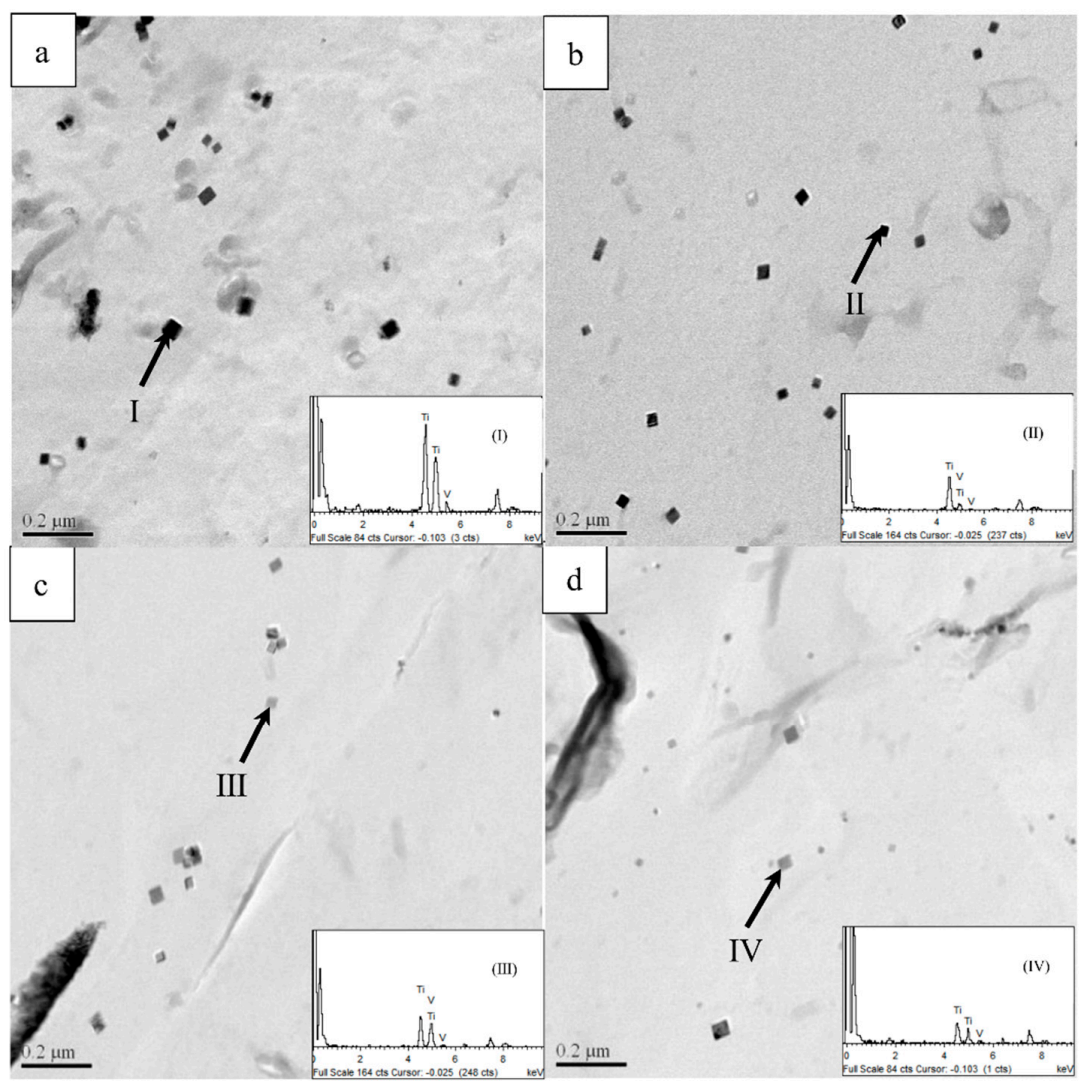

Figure 7. TEM observation of the precipitates in the simulated samples of (a) $120 \mathrm{~kJ} / \mathrm{cm}$, (b) $85 \mathrm{~kJ} / \mathrm{cm}$, (c) $65 \mathrm{~kJ} / \mathrm{cm}$, and (d) $35 \mathrm{~kJ} / \mathrm{cm}$ and their EDS analysis results. 
Figure 8 displays the XRD patterns of simulated samples at different heat inputs. The quantitative test results of the dislocation density showed that the average dislocation density $\rho$ slightly increased with a gradual decrease in the heat inputs as summarized in Table 2.

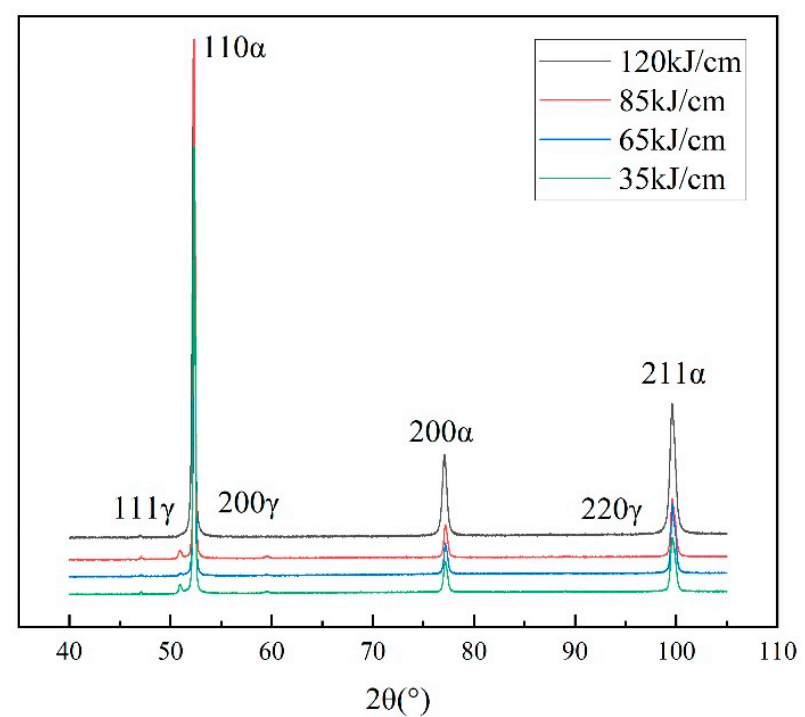

Figure 8. XRD spectra of the samples with different heat inputs from 120 to $35 \mathrm{~kJ} / \mathrm{cm}$.

The changes in the reverse polarity diagram of each sample are shown in Figure 9. The inverse pole figures of microstructure in CGHAZ, where the high-angle grain boundaries (HAGB) with an MTA higher than $15^{\circ}\left(\theta>15^{\circ}\right)$ is represented by black lines, and the low-angle grain boundary (LAGB) with an MTA varied from 2 to $15^{\circ}\left(2^{\circ} \leq \theta \leq 15^{\circ}\right)$ is represented by white lines. The percentage of low-angle grain boundaries $2^{\circ} \leq \theta \leq 15^{\circ}$

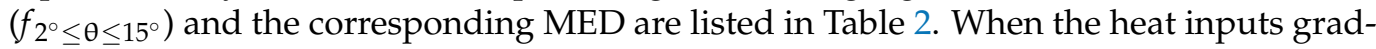

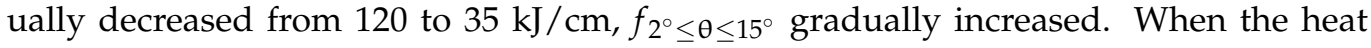
input steadily decreased from 120 to $65 \mathrm{~kJ} / \mathrm{cm}$, MED defined by the MTA lower than $15^{\circ}$ decreased from 24.48 to $2.83 \mu \mathrm{m}$. With a gradual decrease in the heat input from 65 to $35 \mathrm{~kJ} / \mathrm{cm}$, when MTA varied from 2 to $15^{\circ}$, MED sharply increased from 2.83 to $4.88 \mu \mathrm{m}$. As Figure 9e,f shows, the grain size of IGAF at heat input of $65 \mathrm{~kJ} / \mathrm{cm}$ was significantly refined compared with that of GB at heat input of $35 \mathrm{~kJ} / \mathrm{cm}$. Figure 10 shows MED for the misorientation tolerance angle (MTA) in the range of $2-30^{\circ}$ and varying with heat input; the MED increased monotonically with the increase of MTA and heat input, respectively. 

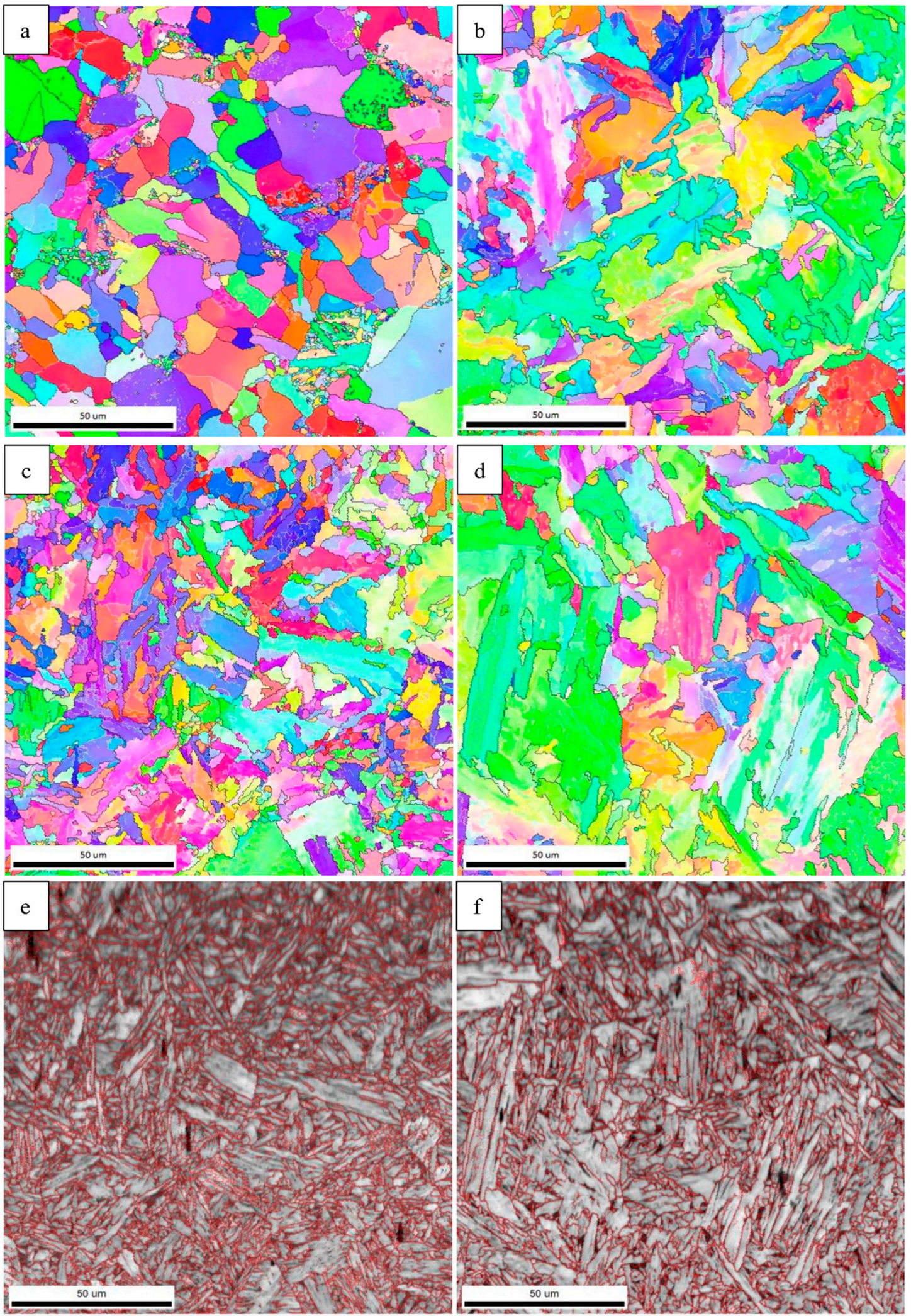

Figure 9. EBSD inverse pole figure for the simulated samples of (a) $120 \mathrm{~kJ} / \mathrm{cm},(\mathbf{b}) 85 \mathrm{~kJ} / \mathrm{cm}$, (c) $65 \mathrm{~kJ} / \mathrm{cm}$, and (d) $35 \mathrm{~kJ} / \mathrm{cm}$ with the white and black lines expressing the misorientation tolerance angle in the range of $2-15^{\circ}$ and greater than $15^{\circ}$, respectively; image quality maps for the simulated samples of (e) $65 \mathrm{~kJ} / \mathrm{cm}$ and (f) $35 \mathrm{~kJ} / \mathrm{cm}$ with the red lines expressing the misorientation tolerance angle greater than or equal $2^{\circ}$. 


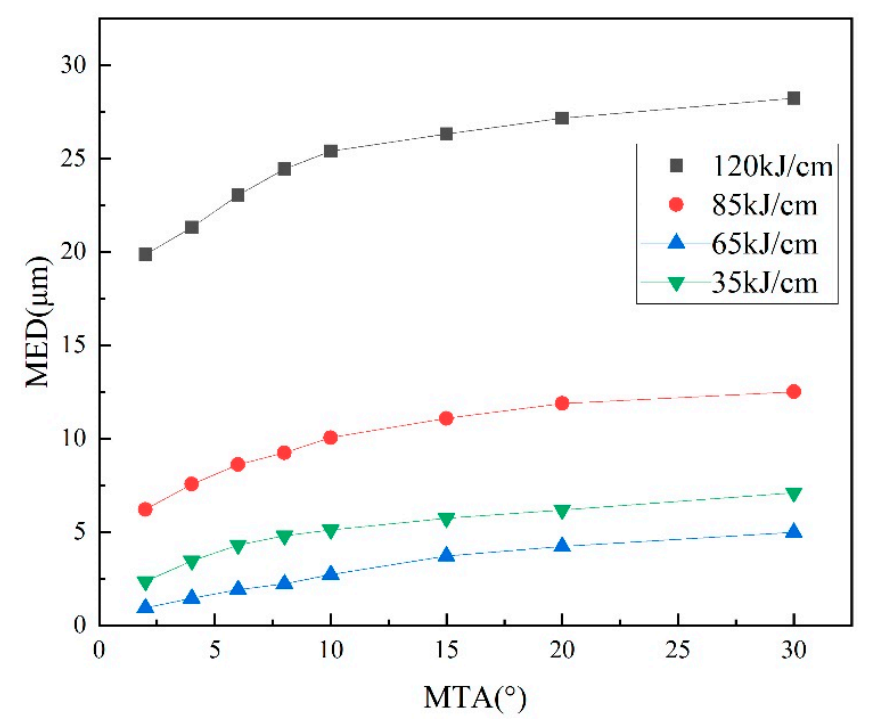

Figure 10. EBSD MED as functions of MTA and the heat input.

\section{Discussion}

\subsection{Microstructure Evolution Process}

At the heat input of $120 \mathrm{~kJ} / \mathrm{cm}$, the microstructures of the samples were IGPF and P. When the heat input was $65 \mathrm{~kJ} / \mathrm{cm}$, the microstructures were mainly IGAF. As the heat input decreased from 120 to $65 \mathrm{~kJ} / \mathrm{cm}$, ferrite changed from IGPF to IGAF. IGPF is a diffusion transformation controlled by diffusion and migration of solute atoms near the phase interface [30]. When the heat input was $120 \mathrm{~kJ} / \mathrm{cm}$ (relatively higher), the carbon atoms diffused sufficiently. Meanwhile, the growth rate of ferrite is irrelevant to the boundary orientation. Therefore, IGPF was formed [31]. Since the diffusion rate of atoms gradually decreased with a gradual decrease in the heat input, when the heat input was $65 \mathrm{~kJ} / \mathrm{cm}$ (relatively lower), the diffusion rate of carbon atoms was lower and the transformation of IGPF was inhibited. The non-diffusion phase transformation is more likely to occur at lower temperatures, instead of the diffusion-controlled phase transformation of P or IGPF [30]. Meanwhile, as Figure 11 shows, $(\mathrm{Ti}, \mathrm{V})(\mathrm{C}, \mathrm{N})$ provided abundant nucleation sites for IGAF [32]. So, the microstructure obtained at the heat input of $65 \mathrm{~kJ} / \mathrm{cm}$ consisted of IGAF and a small amount of GB. At low undercooling, IGPF of the diffusion transformation was dominant, and IGPF might nucleate at the precipitates or inclusions in grains or the grain boundaries of austenite. However, when the undercooling is large, the IGAF transformation is dominated by the nucleation of precipitates or inclusions in grains $[6,33,34]$. With a gradual decrease in the heat input, the undercooling increased, and the ferrite morphology tended to change from IGPF to IGAF.

At the heat inputs of $35 \mathrm{~kJ} / \mathrm{cm}$, the microstructures of the samples were mainly GB. This was mainly due to a decrease in the number of precipitated particles with smaller sizes and reduced surface energy at lower temperatures [35]. This status could not provide favorable positions for the nucleation of IGAF and did not promote the occurrence of the IGAF transformation [30]. In this case, the GB transformation was promoted at the austenite grain boundary where the nucleation was located. Moreover, due to the large supercooling degree, the nucleation rate of GB was extremely high. GB rapidly nucleated at the grain boundary and grew into the grain [36], which further inhibited the transformation of IGAF. Therefore, GB was the main microstructure obtained at the heat input of $35 \mathrm{~kJ} / \mathrm{cm}$.

Pearlite is a diffusion-controlled transformation, so its growth requires the diffusion of all elements [37]. Therefore, the diffusion process was inhibited, and the fraction of pearlite decreased until it disappeared as the heat input continued to decrease from 120 to $65 \mathrm{~kJ} / \mathrm{cm}$. 


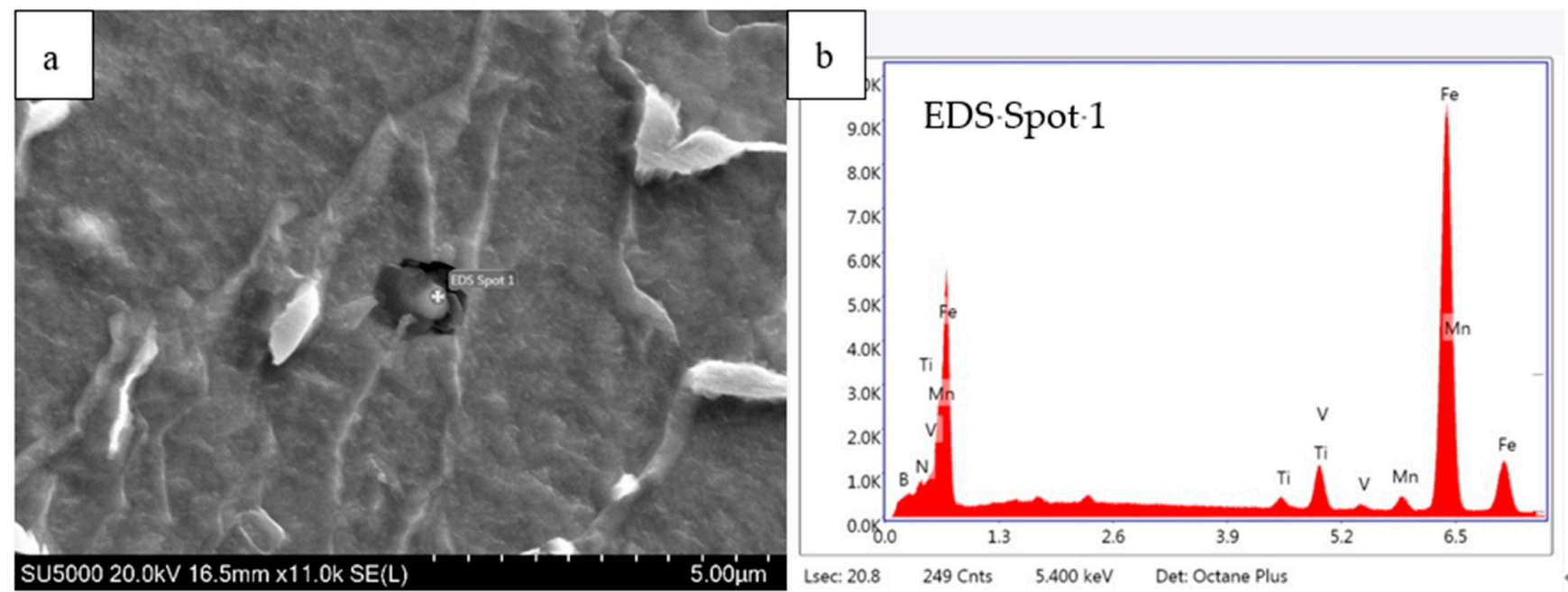

Figure 11. Typical SEM micrograph of IGAF nucleating possibly at a $(\mathrm{Ti}, \mathrm{V})(\mathrm{C}, \mathrm{N})$ particle (a) and EDS analysis of the corresponding particle (b).

After the ferrite transformation, some of the carbon-rich austenite was retained. During the subsequent cooling process, a part of carbon-rich austenite transformed to martensite resulting in the coexistence of retained austenite and martensite, namely the $\mathrm{M} / \mathrm{A}$ constituent [38]. The emergence of the $\mathrm{M} / \mathrm{A}$ is associated with the dispersion of carbon from ferrite to untransformed austenite [39]. The diffusivity of carbon markedly dropped with a gradual decrease in the heat input [18]. The low heat input limits the diffusion of carbon and inhibits the formation of untransformed austenite. The mean size and the area fraction of the M/A island sharply decreased with a gradual decrease in the heat inputs.

\subsection{Strength Contribution Fraction}

The microstructural features such as the grain size, the dislocations, and the precipitated particles changed with the change in the heat input (Table 2) making different contributions to the yield strength. According to the literature [40], YS $\left(\sigma_{\mathrm{y}}\right)$ of the lowcarbon micro-alloyed bainitic steel can be calculated by the linear superposition of a single strengthening factor, and can be expressed as follows:

$$
\sigma_{\mathrm{y}}=\sigma_{0}+\sigma_{\mathrm{d}}+\sigma_{\rho}+\sigma_{\mathrm{p}}+\sigma_{\mathrm{s}}+\sigma_{\mathrm{M}}
$$

where $\sigma_{0}$ is the Peierls-Nabarro stress, $\sigma_{\mathrm{d}}$ is the fine-grain strengthening, $\sigma_{\rho}$ is the dislocation strengthening, $\sigma_{\mathrm{p}}$ is the precipitation strengthening, $\sigma_{\mathrm{s}}$ is the solid solution strengthening and $\sigma_{\mathrm{M}}$ is the strengthening caused by other factors. The contribution of different strengthening methods to the YS will be discussed here.

According to the Hall-Petch relationship [41,42], the relationship between $\sigma_{\mathrm{y}}$ and the grain size $d$ can be given by the following formula:

$$
\sigma_{\mathrm{y}}=\sigma_{0}^{*}+k_{\mathrm{HP}} d^{-1 / 2}
$$

where $\sigma_{0}^{*}$ is the other mechanisms contributing to the strengthening and $k_{\mathrm{HP}} d^{-1 / 2}$ is the fine-grained strengthening contribution. In this paper, $k_{\mathrm{HP}}$ was a structural constant that was related to the properties of the material. $d$ is the effective MED defined by a certain MTA $(\theta)$. Studies $[43,44]$ suggested that low angle grain boundaries can effectively control the dislocation motion and the effective grain size defined by $2-15^{\circ}$ misorientation is the microstructural unit to control YS $[45,46]$. As can be seen from Figure 12, YS of the samples processed at different heat inputs was linearly correlated with the reciprocal square root of 
the effective grain size $\left(\mathrm{MED}^{-1 / 2}\right)$ in the MTA range of $2-15^{\circ}$ with the correlation coefficient of 0.99 . The corresponding linear regression model is written as follows:

$$
\sigma_{\mathrm{d}}=285+17.70 d^{-1 / 2}
$$

The strengthening contribution of effective grains in simulated steels at different heat inputs is summarized in Table 3. As shown in this table, with a gradual decrease in the heat input, the contribution of the fine-grained strengthening increased at first and then decreased. The grain refining efficiency of IGAF was more significant than that of GB, and the grain refinement of IGPF was the weakest among the three.

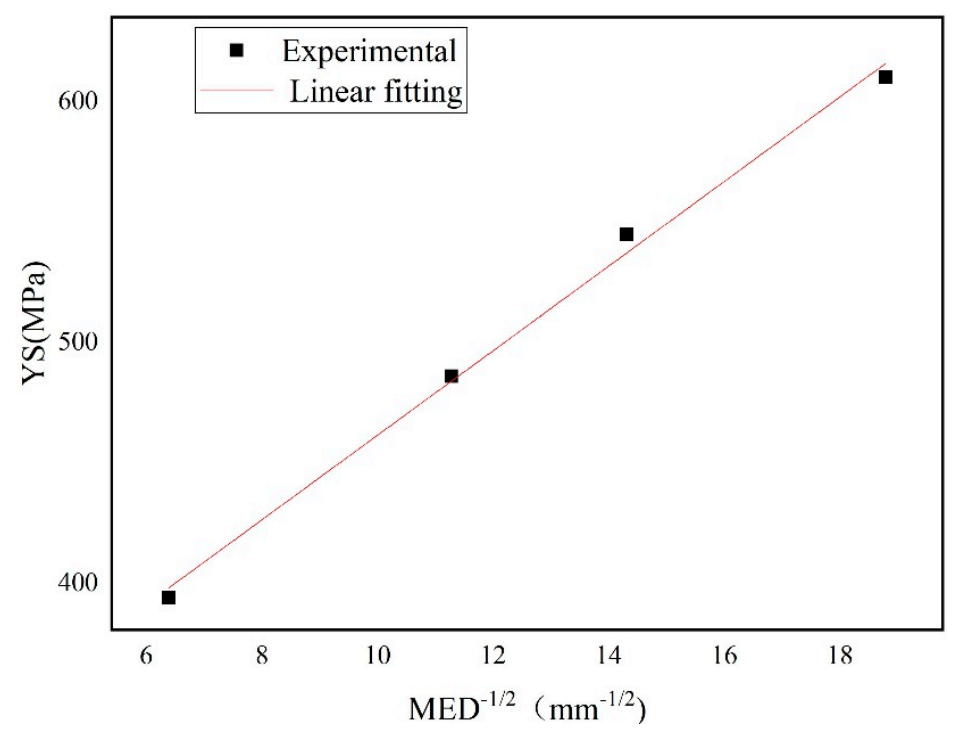

Figure 12. Function relationship between $Y S$ of samples at different heat inputs and the $\mathrm{MED}^{-1 / 2}$ in the MTA range of $2-15^{\circ}$.

The calculation formula of dislocation density $\rho$ is:

$$
\rho=\frac{6 \pi \varepsilon^{2}}{b^{2}}
$$

where $\varepsilon$ is the uneven distribution strain and $b$ represents the Burgers vector of the dislocation in $\alpha$-Fe. $\varepsilon$ and $b$ were resolved by the XRD line profiles.

The contribution of the dislocation strengthening $\left(\sigma_{\rho}\right)$ to the yield strength can be expressed by Equation (5) [47]:

$$
\sigma_{\rho}=\alpha M G b \rho^{1 / 2}
$$

where $\alpha$ is a constant (0.15) [47], $M$ is the Taylor factor of the bainite steel (2.73) [48], $G$ is the shear modulus ( $81.6 \mathrm{GPa}), b$ is the Burger's vector $(0.248 \mathrm{~nm})$ and $\rho$ is the dislocation density given by the measured values shown in Table 2. The contribution of the dislocation to YS of each sample is listed in Table 3. With a gradual decrease in the heat input, the average dislocation density increased, increasing the contribution of the dislocation strengthening.

When Ti is contained in the steel, $(\mathrm{Ti}, \mathrm{V})(\mathrm{C}, \mathrm{N})$ particles can be precipitated in ferrite with a large number and a small size, and the strengthening effect is relatively significant $[48,49]$. As shown in Figure 7 , the precipitated particles with the average size of $17 \sim 33 \mathrm{~nm}$ (Table 2) were formed in the steel. The contribution to the yield strength can be represented by Equation (6).

$$
\sigma_{\mathrm{ppt}}=\frac{11.3 f_{\mathrm{p}}^{1 / 2}}{D_{\mathrm{P}}} \ln \left(\frac{D_{\mathrm{P}}}{0.496}\right) \times 10^{3}
$$


where $f_{\mathrm{P}}$ and $D_{\mathrm{p}}$ are the volume fraction and the average particle size of precipitated particles respectively, which is given by the measured values in Table 2 . The contribution of precipitated particles to the yield strength is listed in Table 3. As this table shows, a decrease in the heat input led to a decrease in $D_{\mathrm{p}}$ and $f_{\mathrm{p}}$ but the precipitation strengthening contribution is close.

Except for the above strengthening factors, $\sigma_{0}$ represents the Peierls-Nabarro stress in $\alpha$-Fe (43) [50], $\sigma_{S}+\sigma_{\mathrm{M}}$ is another strengthening factor of the simulated sample, and the supplementary contribution to the YS is also listed in Table 3. As can be seen from Figure 13, the sum of these two strengthening contributions of YS decreased from 11 to $8 \%$ with a gradual decrease in the heat input. At the heat input of $120 \mathrm{~kJ} / \mathrm{cm}$, the main strengthening methods were fine-grain strengthening, dislocation strengthening and other strengthening methods, moreover, the contribution fraction of these three strengthening methods were about $25 \%$ with little difference. As shown in Figure 13, the contribution of the fine-grain strengthening to YS increased from $28 \%$ at heat input of $120 \mathrm{~kJ} / \mathrm{cm}$ to $53 \%$ at heat input of $65 \mathrm{~kJ} / \mathrm{cm}$, and then decreased to $48 \%$ at heat input $35 \mathrm{~kJ} / \mathrm{cm}$. As the heat inputs gradually decreased from 120 to $35 \mathrm{~kJ} / \mathrm{cm}$, the contribution fractions of the dislocation strengthening and the precipitation strengthening to YS were basically similar. These contribution fractions are the lowest at the heat input of $65 \mathrm{~kJ} / \mathrm{cm}$. Comparing each strengthening contribution with all the microstructure factors, it can be concluded that the effective grain was the most primary structural factor contributing to the YS of the simulated samples followed by dislocation and the precipitates.

On the other hand, as the heat input of the simulated samples decreased, the dislocation density increased, resulting in an increase in the strengthening contribution. However, when the IGAF content was high, the effective grain size decreased and the fine-grain strengthening effect was enhanced remarkably. Consequently, the yield strength reached its highest value at the heat input of $65 \mathrm{~kJ} / \mathrm{cm}$.

Table 3. Summary of individual strengthening contribution of various microstructural features of all the samples.

\begin{tabular}{ccccccc}
\hline $\begin{array}{c}\text { Heat } \\
\text { Input/kJ/cm }\end{array}$ & $\begin{array}{c}\sigma_{\mathbf{0}} \\
/ \mathbf{M P a}\end{array}$ & $\mathbf{Y S} / \mathbf{M P a}$ & $\begin{array}{c}\sigma_{\mathbf{s}}+\sigma_{\mathbf{M}} \\
/ \mathbf{M P a}\end{array}$ & $\begin{array}{c}\sigma_{\mathbf{d}} \\
\text { (MED)/MPa }\end{array}$ & $\sigma_{\boldsymbol{\rho}} / \mathbf{M P a}$ & $\sigma_{\mathbf{p p t}} / \mathbf{M P a}$ \\
\hline 120 & 394 & 43 & 97 & 109 & 100 & 45 \\
85 & 486 & 43 & 65 & 201 & 134 & 43 \\
65 & 610 & 43 & 47 & 325 & 152 & 43 \\
35 & 545 & 43 & 31 & 260 & 161 & 51 \\
\hline
\end{tabular}

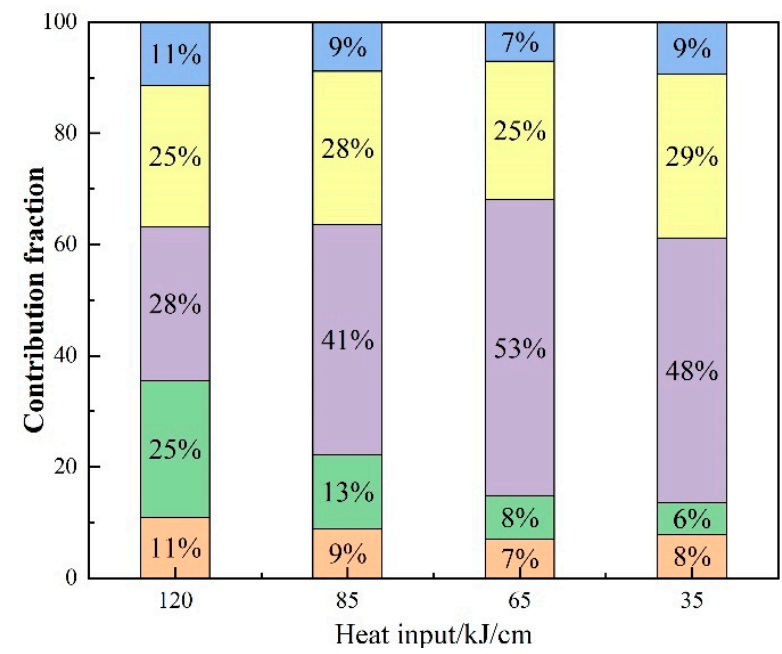

precipitation strengthening dislocation strengthening fine-grain strengthening other strengthening methods the Peierls-Nabarro stress

Figure 13. Contribution rate of various strengthening factors to the yield strength. 


\section{Conclusions}

By studying the ferrite morphology and the tensile properties of the low-C Mo-V-Ti steel after transformation at different heat inputs, we could draw the following conclusions.

(1) A gradual decrease in the heat input from 120 to $65 \mathrm{~kJ} / \mathrm{cm} / 35 \mathrm{~kJ} / \mathrm{cm}$ lead to the change in the dominated microstructure from IGPF to IGAF/GB.

(2) A gradual decrease in the heat input from 120 to $35 \mathrm{~kJ} / \mathrm{cm}$ lead to a decrease at first and then an increase in the effective grain size of ferrite, a slight increase in the dislocation density and restrained the precipitation of valid particles. Meanwhile, YS increased first and then decreased.

(3) As the main microstructure types changed from IGPF to IGAF and GB, the effect of fine-grain strengthening is increasingly remarkable. At the heat input of $65 \mathrm{~kJ} / \mathrm{cm}$, the fraction of IGAF and the contribution of the fine-grain strengthening reached the maximum resulting in the highest YS.

Author Contributions: Data curation, H.F., G.S. and Q.W. (Qiuming Wang); writing-review and editing, Q.W. (Qingfeng Wang); visualization, F.Z; writing—original draft, L.W. All authors have read and agreed to the published version of the manuscript.

Funding: This work is funded by the National Natural Science Foundation of China (Grant no. 51671165).

Institutional Review Board Statement: Not applicable.

Informed Consent Statement: Not applicable.

Conflicts of Interest: The authors declare no conflict of interest.

\section{References}

1. Lee, S.G.; Kim, B.; Sohn, S.S.; Kim, W.G.; Um, K.-K.; Lee, S. Effects of local-brittle-zone (LBZ) microstructures on crack initiation and propagation in three Mo-added high-strength low-alloy (HSLA) steels. Mater. Sci. Eng. A 2019, 760, 125-133. [CrossRef]

2. $\mathrm{Hu}, \mathrm{J}$; $\mathrm{Du}, \mathrm{L}$.-X.; Wang, J.-J.; Gao, C.-R. Effect of welding heat input on microstructures and toughness in simulated CGHAZ of V-N high strength steel. Mater. Sci. Eng. A 2013, 577, 161-168. [CrossRef]

3. Mohammadijoo, M.; Valloton, J.; Collins, L.; Henein, H.; Ivey, D. Characterization of martensite-austenite constituents and micro-hardness in intercritical reheated and coarse-grained heat affected zones of API X70 HSLA steel. Mater. Charact. 2018, 142, 321-331. [CrossRef]

4. Zhang, Y.-Q.; Zhang, H.-Q.; Li, J.-F.; Liu, W.-M. Effect of heat input on microstructure and toughness of coarse grain heat affected zone in $\mathrm{Nb}$ microalloyed HSLA steels. J. Iron Steel Res. Int. 2009, 16, 73-80. [CrossRef]

5. Shi, Z.; Yang, C.; Wang, R.; Su, H.; Chai, F.; Chu, J.; Wang, Q. Effect of nitrogen on the microstructures and mechanical properties in simulated CGHAZ of vanadium microalloyed steel varied with different heat inputs. Mater. Sci. Eng. A 2016, 649, 270-281. [CrossRef]

6. Cheng, L.; Wu, K. New insights into intragranular ferrite in a low-carbon low-alloy steel. Acta Mater. 2009, 57, 3754-3762. [CrossRef]

7. Shim, J.-H.; Cho, Y.; Chung, S.; Lee, D. Nucleation of intragranular ferrite at $\mathrm{Ti}_{2} \mathrm{O}_{3}$ particle in low carbon steel. Acta Mater. 1999, 47, 2751-2760. [CrossRef]

8. Medina, S.F.; Gómez, M.; Rancel, L. Grain Refinement by Intragranular Nucleation of Ferrite in a High Nitrogen Content Vanadium Microalloyed Steel. Scr. Mater. 2008, 58, 1110-1113. [CrossRef]

9. $\mathrm{Hu}, \mathrm{J} . ; \mathrm{Du}, \mathrm{L} . ; \mathrm{Wang}$, J. Effect of $\mathrm{V}$ on intragranular ferrite nucleation of high Ti bearing steel. Scr. Mater. 2013, 68, 953-956. [CrossRef]

10. Furuhara, T.; Shinyoshi, T.; Miyamoto, G.; Yamaguchi, J.; Sugita, N.; Kimura, N.; Takemura, N.; Maki, T. Multiphase Crystallography in the Nucleation of Intragranular Ferrite on MnS+V(C,N) Complex Precipitate in Austenite. ISIJ Int. 2003, 43, 2028-2037. [CrossRef]

11. Thompson, S.W.; Col, D.J.V.; Krauss, G. Continuous cooling transformations and microstructures in a low-carbon, high-strength low-alloy plate steel. Met. Mater. Trans. A 1990, 21, 1493-1507. [CrossRef]

12. $\mathrm{Hu}, \mathrm{J}$; Du, L.-X.; Wang, J.-J; Xie, H.; Gao, C.-R.; Misra, R. High toughness in the intercritically reheated coarse-grained (ICRCG) heat-affected zone (HAZ) of low carbon microalloyed steel. Mater. Sci. Eng. A 2014, 590, 323-328. [CrossRef]

13. Díaz-Fuentes, M.; Iza-Mendia, A.; Gutiérrez, I. Analysis of different acicular ferrite microstructures in low-carbon steels by electron backscattered diffraction. Study of their toughness behavior. Met. Mater. Trans. A 2003, 34, 2505-2516. [CrossRef]

14. Di, X.; Tong, M.; Li, C.; Zhao, C.; Wang, D. Microstructural evolution and its influence on toughness in simulated inter-critical heat affected zone of large thickness bainitic steel. Mater. Sci. Eng. A 2018, 743, 67-76. [CrossRef] 
15. Shi, Z.; Wang, J.; Chai, X.; Wang, S.; Chen, G.; Wang, R. Effect of boron on intragranular ferrite nucleation mechanism in coarse grain heat-affected zone of high-nitrogen steel. Mater. Lett. 2019, 258, 126819. [CrossRef]

16. Shi, Z.; Chai, X.; Chai, F.; Su, H.; Pan, T.; Wang, Q.; Wang, R.; Yang, C. The mechanism of intragranular ferrite formed on Ti-rich $(\mathrm{Ti}, \mathrm{V})(\mathrm{C}, \mathrm{N})$ precipitates in the coarse heat affected zone of a V-N-Ti microalloyed steel. Mater. Lett. 2016, 175, 266-270. [CrossRef]

17. Baker, T.N. Processes, microstructure and properties of vanadium microalloyed steels. Mater. Sci. Technol. 2009, 25, 1083-1107. [CrossRef]

18. Shi, G.; Luo, B.; Zhang, S.; Wang, Q.; Zhao, H. Microstructural evolution and mechanical properties of a low-carbon V-N-Ti steel processed with varied isothermal temperatures. Mater. Sci. Eng. A 2020, 801, 140396. [CrossRef]

19. Fan, H.; Shi, G.; Peng, T.; Wang, Q.; Wang, L.; Wang, Q.; Zhang, F. N-induced microstructure refinement and toughness improvement in the coarse grain heat-affected zone of a low carbon Mo-V-Ti-B steel subjected to a high heat input welding thermal cycle. Mater. Sci. Eng. A 2021, 824, 141799. [CrossRef]

20. Wu, H.; Xia, D.; Ma, H.; Du, Y.; Gao, C.; Gao, X.; Du, L. Study on Microstructure Characterization and Impact Toughness in the Reheated Coarse-Grained Heat Affected Zone of V-N Microalloyed Steel. J. Mater. Eng. Perform. 2021. [CrossRef]

21. Bang, K.-S.; Park, C.; Liu, S. Effects of nitrogen content and weld cooling time on the simulated heat-affected zone toughness in a Ti-containing steel. J. Mater. Sci. 2006, 41, 5994-6000. [CrossRef]

22. Zhang, L.; Kannengiesser, T. Austenite grain growth and microstructure control in simulated heat affected zones of microalloyed HSLA steel. Mater. Sci. Eng. A 2014, 613, 326-335. [CrossRef]

23. Grong, O.; Matlock, D.K. Microstructural Development in Mild and Low-Alloy Steel Weld Metals. Int. Met. Rev. 1986, 31, 27-48. [CrossRef]

24. Miyamoto, G.; Shinyoshi, T.; Yamaguchi, J.; Furuhara, T.; Maki, T.; Uemori, R. Crystallography of intragranular ferrite formed on $(\mathrm{MnS}+\mathrm{V}(\mathrm{C}, \mathrm{N}))$ complex precipitate in austenite. Scr. Mater. 2003, 48, 371-377. [CrossRef]

25. Ricks, R.A.; Howell, P.R.; Barritte, G.S. The nature of acicular ferrite in HSLA steel weld metals. J. Mater. Sci. 1982, 17, 732-740. [CrossRef]

26. Wang, C.; Wu, X.; Liu, J.; Xu, N. Transmission electron microscopy of martensite/austenite islands in pipeline steel X70. Mater. Sci. Eng. A 2006, 438-440, 267-271. [CrossRef]

27. Costin, W.L.; Lavigne, O.; Kotooussov, A. A study on the relationship between microstructure and mechanical properties of acicular ferrite and upper bainite. Mater. Sci. Eng. A 2016, 663, 193-203. [CrossRef]

28. Lee, S.-I.; Lee, J.; Hwang, B. Microstructure-based prediction of yield ratio and uniform elongation in high-strength bainitic steels using multiple linear regression analysis. Mater. Sci. Eng. A 2019, 758, 56-59. [CrossRef]

29. Fan, L.; Wang, T.; Fu, Z.; Zhang, S.; Wang, Q. Effect of heat-treatment on-line process temperature on the microstructure and tensile properties of a low carbon Nb-microalloyed steel. Mater. Sci. Eng. A 2014, 607, 559-568. [CrossRef]

30. Liu, C.; Shi, L.; Liu, Y.; Li, C.; Li, H.; Guo, Q. Acicular ferrite formation during isothermal holding in HSLA steel. J. Mater. Sci. 2015, 51, 3555-3563. [CrossRef]

31. Wu, K.M.; Yokomizo, T.; Enomoto, M. Three-dimensional Morphology and Growth Kinetics of Intragranular Ferrite Idiomorphs Formed in Association with Inclusions in an Fe-C-Mn Alloy. ISIJ Int. 2002, 42, 1144-1149. [CrossRef]

32. Garcia-Mateo, C.; Capdevila, C.; Caballero, F.; De Andrés, C.G. Influence of V Precipitates on Acicular Ferrite Transformation Part 1: The Role of Nitrogen. ISIJ Int. 2008, 48, 1270-1275. [CrossRef]

33. Park, K.-T.; Hwang, S.W.; Ji, J.H.; Lee, C.H. Inclusions nucleating intragranular polygonal ferrite and acicular ferrite in low alloyed carbon manganese steel welds. Met. Mater. Int. 2011, 17, 349-356. [CrossRef]

34. Babu, S.S. The mechanism of acicular ferrite in weld deposits. Curr. Opin. Solid State Mater. Sci. 2004, 8, 267-278. [CrossRef]

35. Zhang, J.; Xin, W.; Luo, G.; Wang, R.; Meng, Q.; Xian, S. Effect of welding heat input on microstructural evolution, precipitation behavior and resultant properties of the simulated CGHAZ in high-N V-alloyed steel. Mater. Charact. 2020, 162, 110201. [CrossRef]

36. García-Mateo, C.; Caballero, F.G.; Bhadeshia, H.K. Mechanical Properties of Low-Temperature Bainite. Mater. Sci. Forum 2005, 500-501, 495-502. [CrossRef]

37. Zhang, X.; Cai, Q.; Zhou, G.; Chen, Q.; Xiong, Y. Microstructure and mechanical properties of V-Ti-N microalloyed steel used for fracture splitting connecting rod. J. Mater. Sci. 2010, 46, 1789-1795. [CrossRef]

38. Chen, H.; Zhang, S.; Shi, G.; Gao, Y.; Wang, Q.; Zhang, F. Mechanism of increased N content in controlling the M-A constituent of low-carbon Mo-V-N steel. Mater. Lett. 2017, 189, 136-139. [CrossRef]

39. Laidler, K.J. The Development of the Arrhenius Equation. J. Chem. Educ. 1984, 61, 494. [CrossRef]

40. Yakubtsov, I.; Poruks, P.; Boyd, J. Microstructure and mechanical properties of bainitic low carbon high strength plate steels. Mater. Sci. Eng. A 2008, 480, 109-116. [CrossRef]

41. O Hall, E. The Deformation and Ageing of Mild Steel: III Discussion of Results. Proc. Phys. Soc. Sect. B 1951, 64, 747-753. [CrossRef]

42. Petch, N.J. The Cleavage Strength of Polycrystals. J. Iron Steel Inst. 1953, 174, 25-28.

43. Kaijalainen, A.J.; Suikkanen, P.P.; Limnell, T.J.; Karjalainen, L.P.; Kömi, J.I.; Porter, D.A. Effect of austenite grain structure on the strength and toughness of direct-quenched martensite. J. Alloys Compd. 2013, 577, S642-S648. [CrossRef]

44. Olasolo, M.; Uranga, P.; Rodriguez-Ibabe, J.; López, B. Effect of austenite microstructure and cooling rate on transformation characteristics in a low carbon $\mathrm{Nb}-\mathrm{V}$ microalloyed steel. Mater. Sci. Eng. A 2011, 528, 2559-2569. [CrossRef] 
45. Gutiérrez, I. Effect of microstructure on the impact toughness of Nb-microalloyed steel: Generalisation of existing relations from ferrite-pearlite to high strength microstructures. Mater. Sci. Eng. A 2013, 571, 57-67. [CrossRef]

46. Fan, L.; Zhou, D.; Wang, T.; Li, S.; Wang, Q. Tensile properties of an acicular ferrite and martensite/austenite constituent steel with varying cooling rates. Mater. Sci. Eng. A 2014, 590, 224-231. [CrossRef]

47. Hughes, D. Microstructure evolution, slip patterns and flow stress. Mater. Sci. Eng. A 2001, 319-321, 46-54. [CrossRef]

48. Rosenberg, J.M.; Piehler, H.R. Calculation of the taylor factor and lattice rotations for bcc metals deforming by pencil glide. Met. Mater. Trans. A 1971, 2, 257-259. [CrossRef]

49. Wang, G.R.; Lau, T.W.; Weatherly, G.C.; North, T.H. Weld thermal cycles and precipitation effects in Ti-V-containing HSLA steels. Met. Mater. Trans. A 1989, 20, 2093-2100. [CrossRef]

50. Nabarro, F. Fifty-year study of the Peierls-Nabarro stress. Mater. Sci. Eng. A 1997, 234-236, 67-76. [CrossRef] 